Check for updates

Cite this: RSC Adv., 2017, 7, 47251

\title{
Role of porosity and polarity of nanoporous carbon spheres in adsorption applications $\uparrow$
}

\author{
Hee Soo Kim, ${ }^{a}$ Seunghun Lee, ${ }^{a}$ Dong Kwan Kim, ${ }^{a}$ Yong-Woo Lee ${ }^{\star a b}$ \\ and Won Cheol Yoo (D)*ab
}

The role of porosity (pore size distribution (PSD) and specific surface area (SSA)) and polarity (N-doping) of carbonaceous materials for selective separation of $\mathrm{CH}_{4}$ over $\mathrm{N}_{2}$ and adsorption of heavy metal ions are presented herein. Two different carbons (resorcinol-formaldehyde carbon (RFC) and highly $\mathrm{N}$-doped melanin carbon $(\mathrm{MC})$ ) with different $\mathrm{N}$-doping levels are utilized and further activated by hot $\mathrm{CO}_{2}$ treatment to finely control PSD and SSA. For $\mathrm{CH}_{4}$ adsorption, the accumulated ultramicropore $(<1 \mathrm{~nm})$ volume of both carbons is strongly correlated with $\mathrm{CH}_{4}$ adsorption regardless of surface polarity of carbons $\left(R^{2}=0.94\right)$. This is probably due to the high polarizability and nonpolar nature of $\mathrm{CH}_{4}$. Carbons with the highest ultramicropore volumes (RFC_C60 and MC_C55) show ultrahigh $\mathrm{CH}_{4}$ uptake capacities of 2.64 and $2.41 \mathrm{mmol} \mathrm{g}^{-1}$ at $273 \mathrm{~K}$ under 1 bar, respectively; these carbons also have superb $\mathrm{CH}_{4}$ over $\mathrm{N}_{2}$ selectivity of 6.8 and 7.4 obtained at $298 \mathrm{~K}$, respectively. RFC_C60 and MC_C55 present excellent $\mathrm{CH}_{4}$ adsorption capacities and selectivities for $\mathrm{CH}_{4}$ over $\mathrm{N}_{2}$, which are comparable with the best values reported from various porous materials. In addition, heavy metal ion $\left(\mathrm{Fe}^{2+}, \mathrm{Sb}^{3+}\right.$, and $\mathrm{Sb}^{5+}$ ) adsorption was achieved to identify the importance of SSA and the polarity of carbons. The SSA of RFC samples is highly correlated with $\mathrm{Fe}^{2+}$ metal ion adsorption capacity $\left(R^{2}=0.98\right)$. Conversely, highly $\mathrm{N}$-doped $\mathrm{MC}$ series are located on the upper region of the plotted line of RFC samples due to their basic nature, which is caused by high loading of N-doping within the carbon framework. Furthermore, RFC_C60 and MC_C55 samples with similar porosity but different $\mathrm{N}$-doping levels are utilized for selective adsorption of $\mathrm{Sb}^{3+}$ over $\mathrm{Sb}^{5+}$. The more basic MC_C55 has higher selectivity of 3.3 compared to that of its less basic counterpart (2.0), strongly inferring that carbon polarity is involved in metal ion adsorption. Distinct correlations between carbon porosity and polarity, adsorption capacity for $\mathrm{CH}_{4}$, ultrahigh selectivity for $\mathrm{CH}_{4}$ over $\mathrm{N}_{2}$, adsorption capacity, and selectivity of metal ions are exclusively elucidated here, providing design principles of nanoporous carbonaceous materials for specific adsorption applications.

Received 24th August 2017 Accepted 2nd October 2017

DOI: 10.1039/c7ra09360h

rsc.li/rsc-advances gels, ${ }^{1}$ activated carbons, ${ }^{2-4}$ zeolites, ${ }^{5,6}$ Metal-Organic Frameworks (MOFs), ${ }^{7-10}$ and microporous organic polymers (MOPs). ${ }^{11}$ For example, ultramicropores $(<1 \mathrm{~nm})$ have a pivotal role in $\mathrm{CH}_{4}$ adsorption and adsorption-based separation of $\mathrm{CH}_{4}$ over $\mathrm{N}_{2}$. The effective separation of $\mathrm{CH}_{4}$ over $\mathrm{N}_{2}$ is needed for unconventional natural gases (UCNs), such as landfill gas and shale gas, ${ }^{7,8,12}$ which inevitably contain impurities such as $\mathrm{CO}_{2}$ and $\mathrm{N}_{2}$. These UCNs need to be upgraded to meet pipeline quality (typically $>90 \%$ methane). ${ }^{13}$ Although adsorption-based separation of $\mathrm{CH}_{4}$ over $\mathrm{N}_{2}$ is an effective process for removing $\mathrm{N}_{2}$ from $\mathrm{UCN}$, the process is difficult due to the similar sizes and nonpolar nature of $\mathrm{CH}_{4}$ and $\mathrm{N}_{2}$. Therefore, adsorbents that are highly selective for $\mathrm{CH}_{4}$ over $\mathrm{N}_{2}$ are needed. Largely developed ultramicropore and moderate adsorbent polarizability have shown improved \footnotetext{
adsorption selectivity for $\mathrm{CH}_{4}$ over $\mathrm{N}_{2}$ (ref. 7 and 14-19) in equilibrium separation. The higher polarizability of $\mathrm{CH}_{4}$ $\left(2.59 \AA^{3}\right)$ over $\mathrm{N}_{2}\left(1.74 \AA^{3}\right)$ mainly accounts for the higher adsorption of $\mathrm{CH}_{4}$ over $\mathrm{N}_{2}$ within ultramicropores. ${ }^{7,14-19} \mathrm{~A}$

${ }^{a}$ Department of Applied Chemistry, Hanyang University, Ansan 15588, Republic of Korea.E-mail: yongwoolee@hanyang.ac.kr; wcyoo@hanyang.ac.kr

${ }^{b}$ Department of Chemical and Molecular Engineering, Hanyang University, Ansan 15588, Republic of Korea

$\dagger$ Electronic supplementary information (ESI) available. See DOI: $10.1039 / \mathrm{c} 7 \mathrm{ra09360h}$
} 
similar trend of $\mathrm{CO}_{2}$ over $\mathrm{N}_{2}$ is due to the higher polarizability of $\mathrm{CO}_{2}\left(2.91 \AA^{3}\right) .{ }^{20-24}$

Recently, MOFs with a 1-D micro-channel have shown outstanding adsorption-based selectivity up to 8.34 at $298 \mathrm{~K}^{7}$ Hyper-cross-linked heterocyclic MOPs also presented high adsorption-based selectivity of 8.0 at $273 \mathrm{~K}$ and 7.6 at $298 \mathrm{~K}^{11}$ However, the adsorption capacities of these MOFs and MOPs at 1 bar with the above temperatures are less than $1 \mathrm{mmol} \mathrm{g}^{-1}$, which is not sufficient for practical purposes.

Recent reports on carbonaceous materials have shown promising adsorption capacity of $\mathrm{CH}_{4}$ at ambient conditions. El-Kaderi et al. synthesized N-doped porous carbons activated by $\mathrm{KOH}$ with outstanding $\mathrm{CH}_{4}$ uptake capacity of $2.7 \mathrm{mmol} \mathrm{g}^{-1}$ at $273 \mathrm{~K}$ and $1.7 \mathrm{mmol} \mathrm{g}^{-1}$ at $298 \mathrm{~K}^{25}$ The Qiu group reported $\mathrm{KOH}$ activated carbons derived from a porous aromatic framework with high $\mathrm{CH}_{4}$ adsorption capacity of $2.4 \mathrm{mmol} \mathrm{g}^{-1}$ at 273 K. ${ }^{19}$ Both research groups reported carbons with ultrahigh $\mathrm{CH}_{4}$ uptake at ambient conditions and ultramicropores developed by a judicious $\mathrm{KOH}$ activation process as the key component.

On the other hand, contamination of water by heavy metal ions is a serious issue for health and environmental reasons due to their toxic and nonbiodegradable properties. ${ }^{26-30}$ For example, antimony $(\mathrm{Sb})$ has been widely utilized in numerous industrial areas, such as production of batteries, ceramics, chemicals, and flame retardants. ${ }^{31-35}$ Antimony species are highly toxic compounds known as high priority pollutants determined by the USEPA and EU, by which the maximum permissible concentrations for $\mathrm{Sb}$ species in drinking water are 6 and $5 \mu \mathrm{g} \mathrm{l^{-1 }}$, respectively. ${ }^{33,35}$ In environmental species, antimony is mainly found in two oxidation states of $\mathrm{Sb}^{3+}$ and $\mathrm{Sb}^{5+}$. Most oxygenated systems contain predominately $\mathrm{Sb}^{5+}$ formed as $\mathrm{Sb}(\mathrm{OH}) 6^{-} \cdot{ }^{32,33} \mathrm{Sb}^{3+}$ mainly formed as $\mathrm{Sb}(\mathrm{OH})_{3}$ is almost ten times more toxic than $\mathrm{Sb}^{5+}$. $31,33,36$

Among various methods for removing heavy metal ions, an adsorption-based removal process is the most widely utilized due to its effectiveness and economic benefits. ${ }^{26,27,29,30}$ In general, large SSA and basic surface functionality of adsorbents forming complexes with metal ions are needed for effective removal of metal ions from aqueous solutions..$^{26-30}$ As efficient adsorbents for metal ion adsorption, carbonaceous materials have been widely implemented due to the aforementioned features. ${ }^{27,29,30}$

Herein, the role of porosity (i.e., PSA and SSA) and polarity (i.e., N-doping) of carbonaceous materials for adsorption applications are presented. Different precursors of resorcinolformaldehyde (RF) and highly N-containing dopamine are utilized to prepare RFC and highly N-doped MC spheres that are further activated by hot $\mathrm{CO}_{2}$ treatment to finely control PSD, SSA, and pore volume. The importance of carbon ultramicroporosity is revealed in that $\mathrm{CH}_{4}$ adsorption and adsorption-based selective separation of $\mathrm{CH}_{4}$ over $\mathrm{N}_{2}$ are strongly correlated with accumulated pore volumes of $0.7 \mathrm{~nm}$ and $1 \mathrm{~nm}$ of both carbons regardless of surface polarity. This result is ascribed to the high polarizability and nonpolar nature of $\mathrm{CH}_{4}$. Carbons with highest ultramicropore volumes show ultrahigh $\mathrm{CH}_{4}$ uptake capacities and superb selectivity for $\mathrm{CH}_{4}$ over $\mathrm{N}_{2}$, comparable with the best results from MOFs, MOPs, zeolites, and carbonaceous materials.

In addition, adsorption of heavy metal ions $\left(\mathrm{Fe}^{2+}, \mathrm{Sb}^{3+}\right.$, and $\mathrm{Sb}^{5+}$ ) is achieved to reveal the role of SSA and polarity of carbons. The SSAs of the RFC series are highly correlated with $\mathrm{Fe}^{2+}$ adsorption capacity $\left(R^{2}=0.98\right)$. Conversely, MC samples are located in the upper region of the plotted line for RFC samples due to their basic nature caused by high loading of $\mathrm{N}$-doping within a carbon framework. Furthermore, RFC_C60 and MC_C55 with similar porosity but different N-doping levels are utilized for selective adsorption of $\mathrm{Sb}^{3+}$ over $\mathrm{Sb}^{5+}$. The more basic MC_C55 has higher selectivity, indicating the role of carbon surface polarity. The structure-property relationship of carbons for adsorption of gas molecules and heavy metal ions is elucidated herein along with design principles of nanoporous carbonaceous materials for use in specific adsorption applications.

\section{Experimental section}

\subsection{Reagents and chemicals}

Resorcinol (Junsei), formaldehyde (38\%, Amresco), dopamine hydrochloride (Sigma Aldrich), and ammonia solution (28\%, Daejung) were used for synthetic carbons. Iron(III) nitrate hexahydrate (99\%, Sigma Aldrich), potassium antimonyl tartrate hemihydrate $(99.5 \%$, Daejung), potassium hexahydroxoantimonate (99\%, Sigma Aldrich), and pH 5 buffer solution (98\%, Daejung) were used for metal ion adsorption experiments. High purity gas was used for all adsorption experiments $\left(\mathrm{N}_{2}\right.$ : $99.999 \%, \mathrm{CH}_{4}$ : $\left.99.95 \%\right)$.

\subsection{Synthesis of RFP, MP and RFC, MC samples}

To synthesize resorcinol-formaldehyde polymers (RFP), resorcinol $(0.14 \mathrm{~g})$ and formaldehyde $(0.16 \mathrm{~g}, 28 \%)$ were mixed with a solution containing $(200 \mathrm{ml})$ deionized water $\left(\mathrm{H}_{2} \mathrm{O}\right)$ and aqueous ammonia $\left(0.7 \mathrm{~g}, 28 \% \mathrm{NH}_{4} \mathrm{OH}\right)$. After stirring for $24 \mathrm{~h}$ at room temperature, the reaction mixture was moved to an oven and was subsequently heated for $24 \mathrm{~h}$ at $90^{\circ} \mathrm{C}$ without stirring. Solid product was recovered by centrifugation and was washed several times with deionized water.

To synthesize melanin polymers (MP), $1.08 \mathrm{~g}$ of dopamine hydrochloride was dissolved in $280 \mathrm{ml}$ of deionized water and $80 \mathrm{ml}$ of ethanol. Under vigorous stirring, $1 \mathrm{ml}$ of aqueous ammonia solution $\left(28 \% \mathrm{NH}_{3}\right.$ (aq.)) was added to a dopamine hydrochloride solution at room temperature. After stirring for 12 hours, melanin-like nanoparticles were retrieved by centrifugation and were washed with deionized water and ethanol several times.

To obtain carbon samples, RFP was heated from ambient temperature to $800{ }^{\circ} \mathrm{C}$ under a $\mathrm{N}_{2}$ atmosphere over $3 \mathrm{~h}$ at a heating rate of $4.3{ }^{\circ} \mathrm{C}$ per min, and then denoted as RFC. In the melanin polymer carbonization process, MP samples underwent carbonization at $800{ }^{\circ} \mathrm{C}\left(\mathrm{N}_{2}\right.$ atmosphere over $3 \mathrm{~h}$ at a heating rate of $4.3{ }^{\circ} \mathrm{C}$ per min). These carbon samples were denoted as MC. 


\section{$2.3 \mathrm{CO}_{2}$ activation process}

$\mathrm{CO}_{2}$ activation was performed using $250 \mathrm{mg}$ of carbon samples. The samples were placed in an alumina boat in a quartz tube in the isothermal zone of a tubular furnace that was purged with flowing nitrogen. The samples were heated to $900{ }^{\circ} \mathrm{C}$ (heating rate $30{ }^{\circ} \mathrm{C}$ per $\mathrm{min}$ ) under inert conditions $\left(\mathrm{N}_{2}\right)$, followed by changing the gas flux to $\mathrm{CO}_{2}$ (1000 cc per min) for various times (e.g., 60, 120, 250, and $380 \mathrm{~min}$ ). $\mathrm{CO}_{2}$ activated carbon samples were denoted as RFC_CX and MC_CX, where $\mathrm{X}$ is $\mathrm{CO}_{2}$ activation time.

\subsection{Adsorption measurements for $\mathrm{Fe}^{2+}$ ion and calculation of adsorption capacity using Langmuir method}

A stock solution of $\mathrm{Fe}$ ions was prepared by dissolving $\mathrm{Fe}\left(\mathrm{NO}_{3}\right)_{2} \cdot 6 \mathrm{H}_{2} \mathrm{O}$ in deionized $\mathrm{pH} 5$ buffer solution at $2.1 \mathrm{mM}$ (410 ppm). Different carbon samples $(10 \mathrm{mg})$ were added to $10 \mathrm{ml}$ of $\mathrm{pH} 5$ buffer solution, and the mixture was stirred for various amounts of time (e.g., 30, 60, 120, 360, and $720 \mathrm{~min}$ ). Next, an aliquot of the sample was removed and centrifuged to separate the solid and liquid. Finally, the concentration of metal ion in the supernatant was analyzed by UV-vis spectrometry. The calibration curve of the different concentrations of $\mathrm{Fe}^{2+}$ and UV-vis results for carbon samples are in the Fig. S1. $\dagger$ The adsorption capacity of adsorbent at equilibrium was calculated by the following equation:

$$
q_{\mathrm{e}}=\frac{\left(C_{0}-C_{\mathrm{e}}\right) V}{W}
$$

where $q_{\mathrm{e}}$ is equilibrium adsorption capacity of adsorbent in $\mathrm{mg}$ $\mathrm{g}^{-1}, C_{0}$ is initial concentration in $\mathrm{mg} \mathrm{l}^{-1}, C_{\mathrm{e}}$ is equilibrium concentration of $\mathrm{Fe}$ ion in $\mathrm{mg} \mathrm{l}^{-1}, V$ is volume in $\mathrm{l}$ of $\mathrm{Fe}$ ion solution, and $W$ is weight in $\mathrm{g}$ of adsorbent (carbon sample).

The isotherm data were correlated with Langmuir models. A Langmuir isotherm is based on monolayer sorption of metal ion on the surface of adsorbent and is described by the following equation:

$$
q_{\mathrm{e}}=\frac{q_{\mathrm{m}} C_{\mathrm{e}} b}{1+C_{\mathrm{e}} b}
$$

where $q_{\mathrm{e}}$ is adsorption capacity of adsorbent in $\mathrm{mg} \mathrm{g}^{-1}$ and $C_{\mathrm{e}}$ is concentration of metal ion in $\mathrm{mg} \mathrm{l}^{-1}$ at equilibrium. The $q_{\mathrm{m}}$ is maximum adsorption capacity of the metal monolayer in $\mathrm{mg}$ $\mathrm{g}^{-1}$, and $b$ is a constant that refers to the bonding energy of adsorption in $1 \mathrm{mg}^{-1}$. According to the Langmuir isotherm model, the metal ion adsorption process occurs at specific homogeneous sites on the absorbent surface with monolayer formation. This model is used to estimate the maximum adsorption capacity ${ }^{37}\left(q_{\mathrm{m}}\right)$.

\subsection{Adsorption measurements for $\mathrm{Sb}^{3+}$ and $\mathrm{Sb}^{5+}$ ions and capacity}

To make Sb(III) 1000 ppm solutions, potassium antimonyl tartrate hemihydrate $(1.38 \mathrm{~g})$ was mixed with a solution containing $(500 \mathrm{ml})$ deionized water $\left(\mathrm{H}_{2} \mathrm{O}\right)$. To make $\mathrm{Sb}(\mathrm{v})$ $1000 \mathrm{ppm}$ solutions, potassium hexahydroxoantimonate (1.08 $\mathrm{g})$ was mixed with a solution containing $(500 \mathrm{ml})$ deionized water $\left(\mathrm{H}_{2} \mathrm{O}\right)$. And the two solutions were mixed $1: 1$ and serial diluted to the target concentration $(50,500 \mathrm{ppb})$. An aqueous solution $(30 \mathrm{ml})$ with a suitable concentration of $\mathrm{Sb}$ ions was shaken with a suitable amount of adsorbent at $20{ }^{\circ} \mathrm{C}$ for a definite period. Acid (hydrochloric acid) and base (potassium hydroxide) solutions were added to adjust $\mathrm{pH}$, which was measured with a digital $\mathrm{pH}$ meter. After removing the adsorbent by centrifugation, the concentrations of anions remaining in the supernatant were determined by anodic stripping voltammetry (PDV 6000 plus, Modern Water, UK) to determine each Sb ion $\left(\mathrm{Sb}^{3+}\right.$ and $\left.\mathrm{Sb}^{5+}\right)$ and inductive coupled plasma mass spectroscopy (NexION 300X, Perkin Elmer, USA) to determine total $\mathrm{Sb}$ ions. The adsorption isotherms were studied with varying initial concentrations of $\mathrm{Sb}$ ions at a fixed dose of adsorbent (10 $\mathrm{mg}$ ). The adsorption density, given as $\mu \mathrm{mol}-\mathrm{Sb} / \mathrm{g}$ adsorbent, was calculated from the residual concentrations of $\mathrm{Sb}$ ions, known initial concentrations of Sb ions $(\mu \mathrm{M})$, and amount of adsorbent used $(\mathrm{g})$.

\subsection{Calculation of Henry's law selectivity}

Selectivity is calculated using the ratio of Henry's law constants, which is estimated from the initial slopes of $\mathrm{CH}_{4}\left(I_{\mathrm{CH}_{4}}\right)$ and $\mathrm{N}_{2}$ $\left(I_{\mathrm{N}_{2}}\right)$ adsorption isotherms (0-0.1 bar):

$$
S=\frac{I_{\mathrm{CH}_{4}}}{I_{\mathrm{N}_{2}}}
$$

\subsection{Töth isotherm calculation for carbon samples}

The Töth model was applied to all of $\mathrm{CH}_{4}$ and $\mathrm{N}_{2}$ adsorption isotherms of activated carbon samples. The Töth isotherm equation can be expressed:

$$
q=\frac{q_{\mathrm{m}} K_{\mathrm{i}} p}{\left[1+\left(K_{\mathrm{i}} p\right)^{n}\right]^{1 / n}}
$$

where $q$ and $q_{\mathrm{m}}$ are the absolute amount adsorbed and the maximum amount adsorbed capacity. $K_{\mathrm{i}}$ is the adsorption constant, related to the adsorption energy and the affinity of gas molecules. $n$ is an exponent related to the heterogeneity of the adsorbent surface.

\subsection{Characterizations}

Low temperature nitrogen adsorption-desorption isotherms were measured at $-196{ }^{\circ} \mathrm{C}$ on an adsorption volumetric analyzer BEL MAX manufactured by BEL, Inc (Japan). $\mathrm{CH}_{4}$ and $\mathrm{N}_{2}$ adsorption isotherms were located at $0{ }^{\circ} \mathrm{C}$ and $25{ }^{\circ} \mathrm{C}$ on the adsorption volumetric analyzer (BEL MINI). All samples were degassed at $200{ }^{\circ} \mathrm{C}$ for $12 \mathrm{~h}$ under static vacuum before adsorption measurements. Specific surface area was determined by the Brunauer-Emmet-Teller (BET) method from nitrogen adsorption isotherms in the relative pressure range of 0.05-0.20. Total pore volume $\left(V_{\mathrm{t}}\right)$ was estimated from the amount of gas adsorbed at relative pressure $P / P_{0}=0.99$. PSD and accumulated pore volume of RFC and MC samples were calculated from adsorption branches of nitrogen sorption isotherms using the NLDFT (nonlocal density functional theory) 
method for slit-like pores available in BEL master software from BEL Inc. The volume of pores below $0.7,1$, and $2 \mathrm{~nm}$ were calculated on the basis of accumulated pore volumes. Isosteric heat of adsorption $\left(Q_{\mathrm{st}}\right)$ was calculated using the ClausiusClapeyron equation. Surface functional groups of carbon samples were determined by recording FTIR spectra on a Varian Corporation (USA) Varian Scimitar 1000 FT-IR. Scanning electron microscopy (SEM) images were obtained with a HITACHI S4800 microscope with accelerating voltage of $15.0 \mathrm{kV}$. Elemental analyses (EA) were obtained using FLASH EA1112. TEM images were recorded on a transmission electron microscope (JEM2100F). UV-vis spectrometer data was recorded by Optizen 2120UV (MECASYS Inc.). The pH value was obtained from is inoLab_IDS Multi 9420 and ICP results was recorded from NexION 300X (Perkin elmer Inc). The zeta potential results were obtained from EPELS-Z1 (Otsuka Inc).

\section{Results and discussion}

\subsection{Synthesis of carbon spheres and their textural features}

Two carbon spheres (RFC and MC) with different N-containing levels are chosen to elucidate the role of porosity and polarity of carbon spheres for $\mathrm{CH}_{4}$ adsorption, adsorption-based separation of $\mathrm{CH}_{4}$ over $\mathrm{N}_{2}$, and heavy metal ion adsorption. First, Monodisperse RFP spheres with size of $548 \pm 23 \mathrm{~nm}$ are synthesized by the modified sol-gel method reported elsewhere $^{38,39}$ (Fig. 1a). RF precursor is polymerized under waterethanol mixture as a solvent with $\mathrm{NH}_{3}$ catalyst for $24 \mathrm{~h}$ and is subsequently aged for $24 \mathrm{~h}$ at $100{ }^{\circ} \mathrm{C}$. It was revealed that $\mathrm{NH}_{3}$ acts as a base catalyst as well as a nitrogen additive, resulting in polymer spheres with nitrogen content less than $2.8 \mathrm{wt} \%$ (Table 1). ${ }^{38}$ Conversely, dopamine is chosen as a precursor to synthesize highly N-containing polymer spheres. Dopamine precursor is cross-linked via spontaneous oxidation under basic ammonia solution with $\mathrm{O}_{2},{ }^{40}$ resulting in melanin-like polymer (MP) spheres with size of $393 \pm 21 \mathrm{~nm}$ and N-content of $19.2 \mathrm{wt} \%$ (Fig. 2a and Table 1). Both carbons are subsequently carbonized at $800{ }^{\circ} \mathrm{C}$ and denoted as RFC and MC. The RFC sphere is reduced to $440 \pm 21 \mathrm{~nm}$, probably due to radial shrinkage during carbonization (Fig. 1b). ${ }^{\mathbf{3 8 4 0 - 4 3}}$ To control PSD and SSA, hot $\mathrm{CO}_{2}$ treatment at $900{ }^{\circ} \mathrm{C}$ is carried out for RFC spheres, denoted as RFC_C50, C120, C250, and C380, respectively, where $C$ indicates $\mathrm{CO}_{2}$ activation time. According to SEM investigation (Fig. 1c-f), the sizes of $\mathrm{CO}_{2}$-activated RFC spheres (RFC_C50, $\mathrm{C} 120, \mathrm{C} 250$, and C380) are reduced to $400 \pm 20,358 \pm 19,301 \pm$ 18 , and $256 \pm 27 \mathrm{~nm}$, respectively, which is attributed to carbon loss during the activation process $\left(\mathrm{CO}_{2}(\mathrm{~g})+\mathrm{C}(\mathrm{s}) \rightarrow\right.$ $2 \mathrm{CO}(\mathrm{g})) \cdot \cdot^{39,41-43}$ Such carbon loss is also identified under TEM investigation, in which the highly porous nature of the RFC_C380 sphere compared to the RFC sphere is observed (Fig. 3a and b). A similar shrinkage trend is observed for $\mathrm{MC}$ reduced to $162 \pm 17 \mathrm{~nm}$, and the sizes of $\mathrm{CO}_{2}$-activated $\mathrm{MC}$ spheres of MC_C55 and C125 are $130 \pm 18$ and $108 \pm 18 \mathrm{~nm}$, respectively (Fig. 2b-d). Successful $\mathrm{CO}_{2}$ activation for MC_C125 with a highly porous nature compared to $\mathrm{MC}$ is also identified under TEM investigation (Fig. $3 \mathrm{c}$ and d).

The textural features of RFC and MC series were analyzed by nitrogen sorption isotherm measurements. As-prepared RFC shows intrinsic microporosity of a type I isotherm (Fig. 4a). As $\mathrm{CO}_{2}$ activation prolongs, the amount adsorbed at low relative pressure abruptly increases, indicating the development of microporosity (Fig. 4a). Features of type IV isotherms appeared for RFC_C250 and C380, in which more carbon loss with longer activation treatment generates larger mesopores (Fig. 4a). ${ }^{\mathbf{3 9 4 1 - 4 3}}$ According to PSD analysis determined by the NLDFT model, sharp increases in ultramicropores centered around 0.6-0.7 nm are identified for RFC_C60 and C120 samples, strongly suggesting that relative fine-tuning of ultramicropores is possible for carbonaceous materials with $\mathrm{CO}_{2}$ activation (Fig. 4b). SSAs
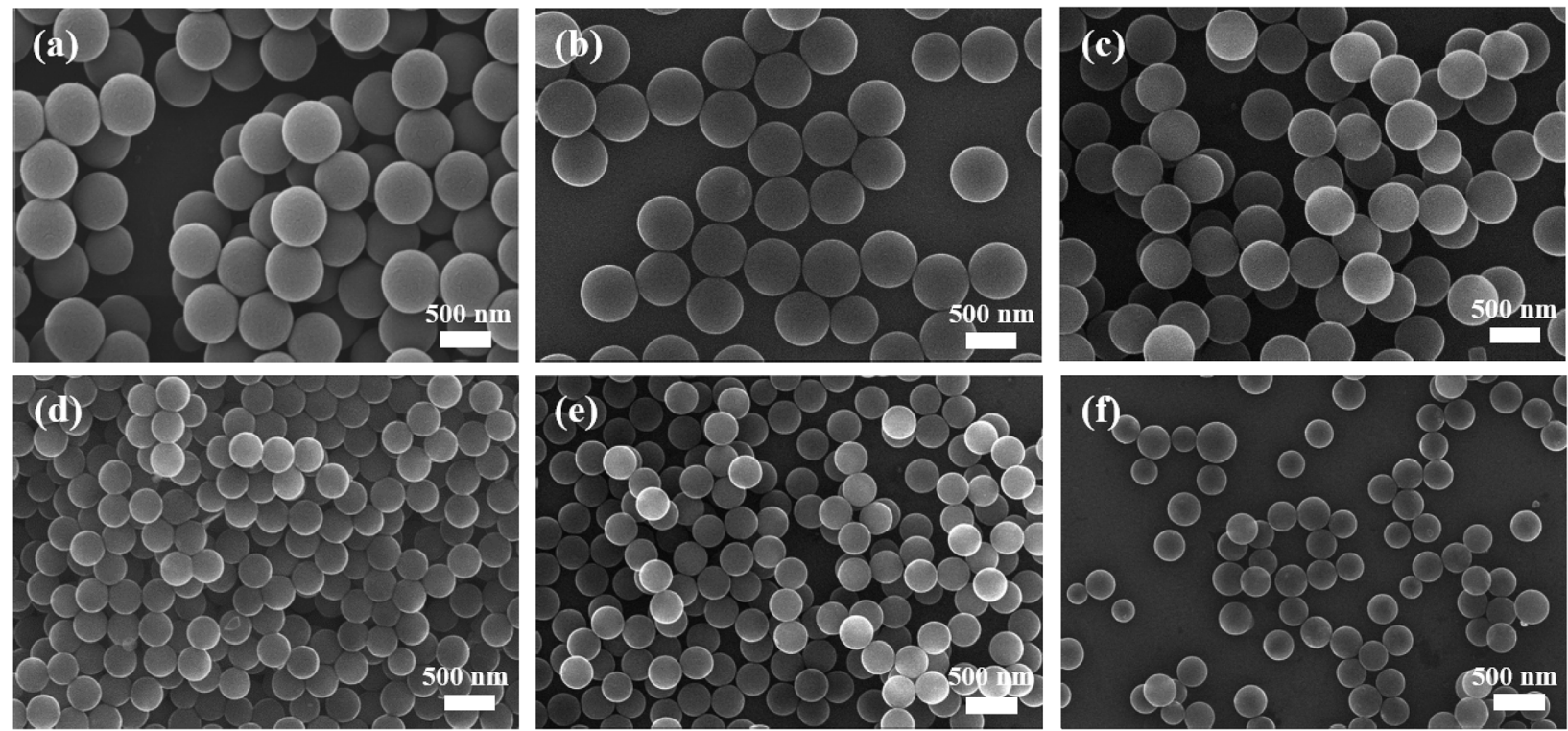

Fig. 1 SEM image of RFP (a), RFC (b), RFC_C60 (c), RFC_C120 (d), RFC_C250 (e) and RFC_C380 (f). 


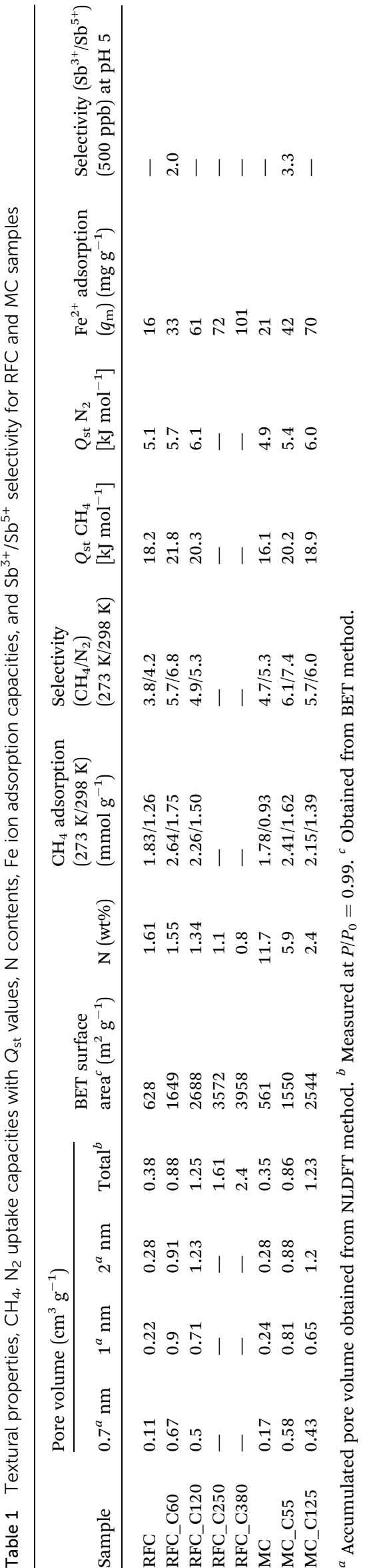

obtained from the BET method for RFC samples (RFC, RFC_C50, C120, C250, and C380) increased from 628 to 1649, 2688,3572 , and $3958 \mathrm{~m}^{2} \mathrm{~g}^{-1}$, respectively, indicating the power of this activation process (Table 1). In addition, a similar pattern was observed for MC samples (MC, MC_C55 and C125). There was a sharp increase in the amount adsorbed at a relative pressure, with abrupt development of ultramicropores around 0.6-0.7 $\mathrm{nm}$ and large increases in SSAs from 561 to 1550 and $2544 \mathrm{~m}^{2} \mathrm{~g}^{-1}$, respectively (Fig. $4 \mathrm{c}$ and d, and Table 1 ).

The nitrogen contents of RFC series (RFC, RFC_C60, C120, 250 , and C380) are 1.61, 1.55, 1.34, 1.1, and $0.8 \mathrm{wt} \%$ (Table 1), respectively, indicating a gradual decrease in nitrogen content that is probably due to the less stabilized nature of nitrogen species during activation. ${ }^{38}$ In contrast, the nitrogen contents of MC series (MC, MC_C55, and C125) are 11.7, 5.9, and 2.4 wt\%, definitely showing higher nitrogen content than the RFC series (Table 1). There are huge nitrogen content differences of 1.55 and 5.9 wt\% for RFC_C60 and MC_C55, respectively. Considering the similar textural features, SSA, and PSD of both carbons, a polarity issue derived from N-doping could be of interest in specific adsorption applications. FR-IR measurements (Fig. 5 and Table S1†) identify the development of several peaks indicating nitrogen species within the carbon framework: $1260 \mathrm{~cm}^{-1}$ for out of plane mode of pyrrole ring, $1389 \mathrm{~cm}^{-1}$ for $\mathrm{C}-\mathrm{N}$ stretching, and $1405 \mathrm{~cm}^{-1}$ for vibration peak of $\mathrm{N}=\mathrm{O}$.

According to the zeta potential measurements for all carbon samples, it is identified that as prolonged $\mathrm{CO}_{2}$-activation process, the zetapotential values slightly and gradually changes from $-14 \mathrm{mV}$ (RFC) to $-7 \mathrm{mV}$ (RFC_C380) in the Fig. S2. $\dagger$ This is probably that hot $\mathrm{CO}_{2}$ treatment at $900{ }^{\circ} \mathrm{C}$, relatively less stable $\mathrm{N}$ moiety is more damaged and disappeared easily, eventually reducing the surface polarity of the carbons with prolonged $\mathrm{CO}_{2}$-activation, which also identified from the $\mathrm{N}$ contents obtained from EA analysis in the Table 1. Similarly, the zetapotential values from $-26,-22$, and $-19 \mathrm{mV}$ were identified for MC and MC_C55 and C125 samples, respectively (Fig. S2 $\dagger$ ), confirming the disappearance of $\mathrm{N}$ content along prolonged $\mathrm{CO}_{2}$-activation process, in which the decrease of $\mathrm{N}$ content is also observed from EA analysis (Table 1).

\subsection{Adsorption-based separation of $\mathrm{CH}_{4}$ over $\mathrm{N}_{2}$ : role of ultramicroposity}

$\mathrm{CH}_{4}$ adsorption isotherms for RFC samples (RFC, RFC_C60, and C120) and MC samples (MC, MC_C55, and C125) are measured at $273 \mathrm{~K}$ and $298 \mathrm{~K}$ (Fig. 6 and $\mathrm{S} 3 \dagger$ ). The $\mathrm{CH}_{4}$ uptake capacities of RFC samples (RFC, RFC_C60, and C120) at $273 \mathrm{~K}$ (1 bar) are $1.83,2.64$, and $2.26 \mathrm{mmol} \mathrm{g}^{-1}$, respectively; those of MC samples are 1.78, 2.41, and $2.15 \mathrm{mmol} \mathrm{g}^{-1}$, respectively (Fig. 6a and $\mathrm{b}$ and Table 1). $\mathrm{CH}_{4}$ adsorption capacities of $2.64 \mathrm{mmol} \mathrm{g}^{-1}$ for RFC_C60 and $2.41 \mathrm{mmol} \mathrm{g}^{-1}$ for MC_C60 at $273 \mathrm{~K}$ (1 bar) are ranked among the highest $\mathrm{CH}_{4}$ uptake capacities from MOFs, MOPs, and carbonaceous materials (Table 2). In addition, $\mathrm{CH}_{4}$ adsorption capacities of RFC samples (RFC, RFC_C60, and C120) and MC samples (MC, MC_C55, and C125) at $298 \mathrm{~K}$ (1 bar) are $1.26,1.75$, and 1.50 , and $0.93,1.62$, and $1.39 \mathrm{mmol} \mathrm{g}^{-1}$, respectively, demonstrating the ultrahigh $\mathrm{CH}_{4}$ adsorption 

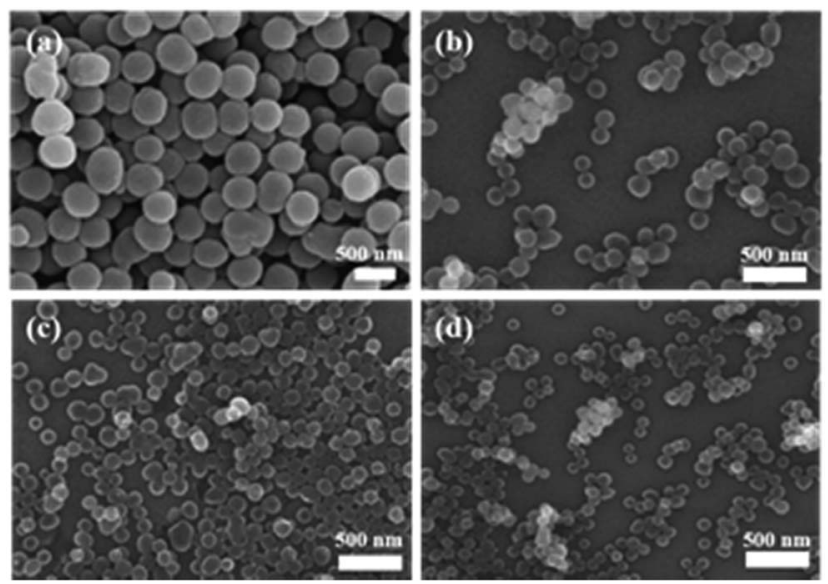

Fig. 2 SEM images of MP (a), MC (b), MC_C55 (c), and MC_C125 (d).

ability of both carbons (Fig. S3, † Tables 1 and 2). Strong correlation is observed between the accumulated ultramicropore volumes $(<0.7 \mathrm{~nm}$ and $<1 \mathrm{~nm})$ for both RFC and MC series and $\mathrm{CH}_{4}$ adsorption capacities (Fig. $6 \mathrm{c}$ and d). Both carbons (RFC_C60 and MC_C55) with higher accumulated ultramicropore volumes present the highest $\mathrm{CH}_{4}$ uptake capacities compared to others, strongly suggesting how to effectively enhance adsorption capacity within ultramicropores for small $\mathrm{CH}_{4}$ molecules (3.80 ̊). ${ }^{2,37}$

$\mathrm{N}_{2}$ adsorption isotherms for RFC and MC series are measured at $273 \mathrm{~K}$ and $298 \mathrm{~K}$ (Fig. $6 \mathrm{a}$ and b, S3a and b and S4d and $\mathrm{e}^{\dagger}$ ). Unlike $\mathrm{CH}_{4}$ adsorption, which is well correlated with ultramicropore volumes, $\mathrm{N}_{2}$ adsorption is well correlated with the SSA $\left(R^{2}=0.95\right)$ of both carbon samples (Fig. $6 \mathrm{f}$ and $\mathrm{S} 3 \mathrm{f} \dagger$ ). There is no relationship between surface polarity and $\mathrm{N}_{2}$ loading levels, which is probably ascribed to the moderate polarity of the carbon surface and small quadrupole moment of
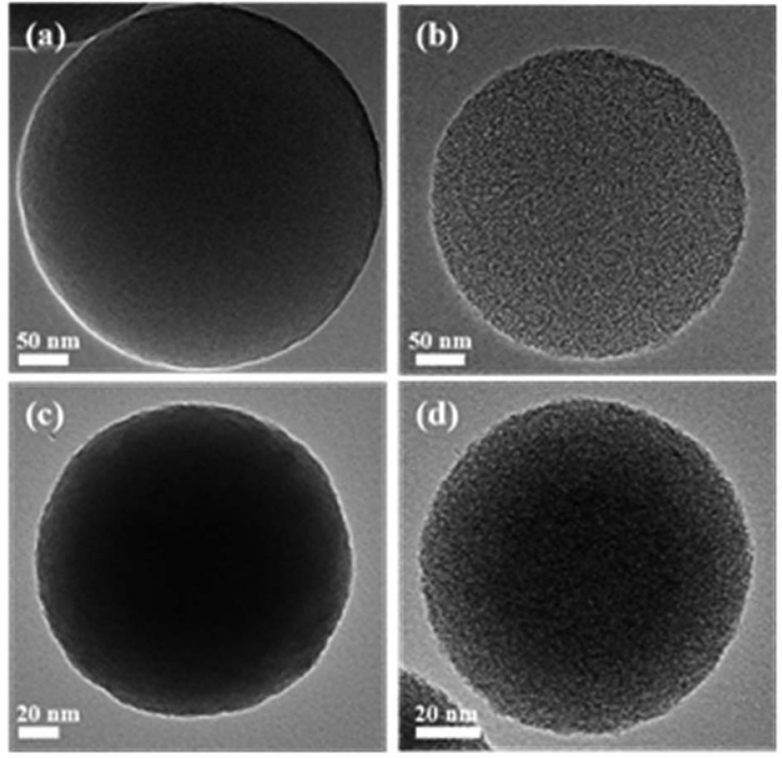

Fig. 3 TEM images of RFC (a), RFC_C380 (b), MC (c), and MC_C125 (d). (a)

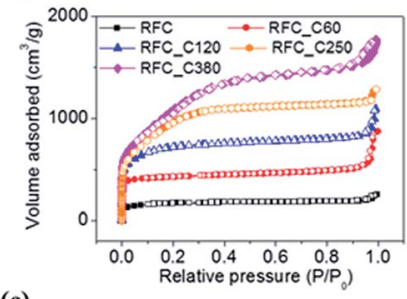

(c)

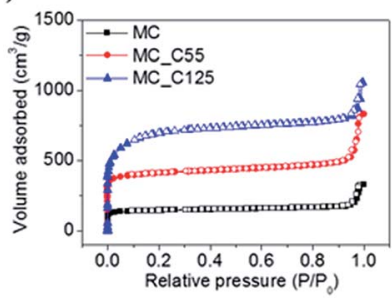

(b)

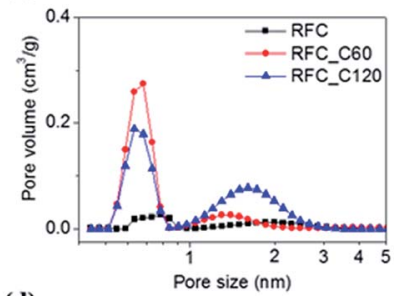

(d)

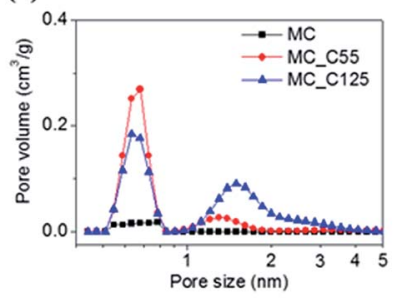

Fig. 4 Nitrogen isotherm of RFC (a) and MC (c) samples at $77 \mathrm{~K}$. Pore size distribution of RFC (b) and MC (d) samples by NLDFT method.

$\mathrm{N}_{2}\left(-4.72 \times 10^{-40} \mathrm{~cm}^{2}\right)^{2}$. The $Q_{\text {st }}$ values for RFC_C60 and MC_C55 are 5.7 and $5.4 \mathrm{~kJ} \mathrm{~mol}^{-1}$, respectively. Considering the nitrogen content of both carbons, 1.55 and $5.9 \mathrm{wt} \%$, respectively, the polarity effect for $\mathrm{N}_{2}$ adsorption does not exist for either carbon series (Table 1).

All the $\mathrm{CH}_{4}$ and $\mathrm{N}_{2}$ isotherms were well fitted to Töth model (Fig. 6a and $\mathrm{b}$ and S3a and $\mathrm{b} \dagger$ ) and the parameters of the fitting are presented in Table $\mathbf{S} 2 . \dagger$ The Töth model is a semi-empirical expression that effectively describes many systems with submonolayer coverage and presents correct behavior at both the low and high pressure ends, reducing deviation errors between experimental data and calculated values of adsorption equilibrium. ${ }^{44-49}$ It is noteworthy that the parameter $n$ presents the system heterogeneity. ${ }^{22,44-49}$ If it the heterogeneity parameter $n$ becomes unity, it is identical to the Langmuir model presenting homogeneous surface; in contrast, if this parameter is lower than unity, the more heterogeneous system is expected. ${ }^{\mathbf{4 4 - 4 6}}$ According to the heterogeneity parameters of $\mathrm{CH}_{4}$ on the carbon samples (Table $\mathrm{S} 2 \dagger$ ), the values are in the range 0.5-0.67,

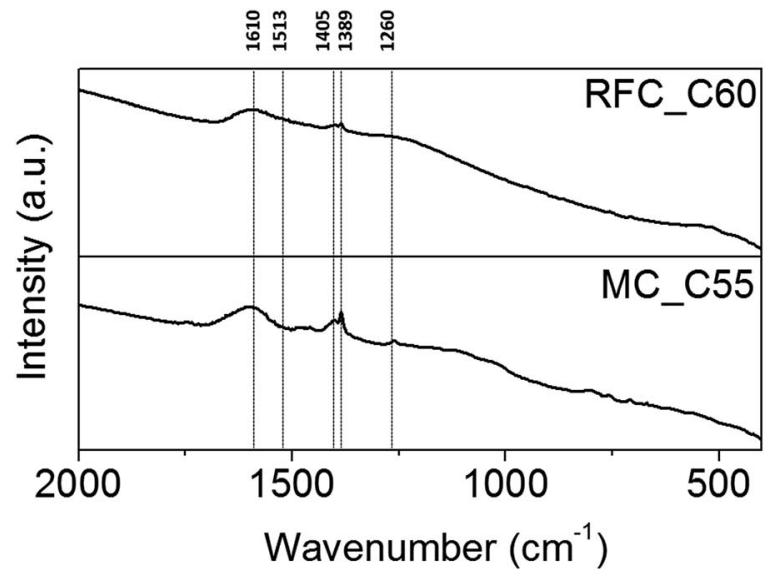

Fig. 5 FT-IR spectra of RFC_C60 and MC_C55. 
(a)
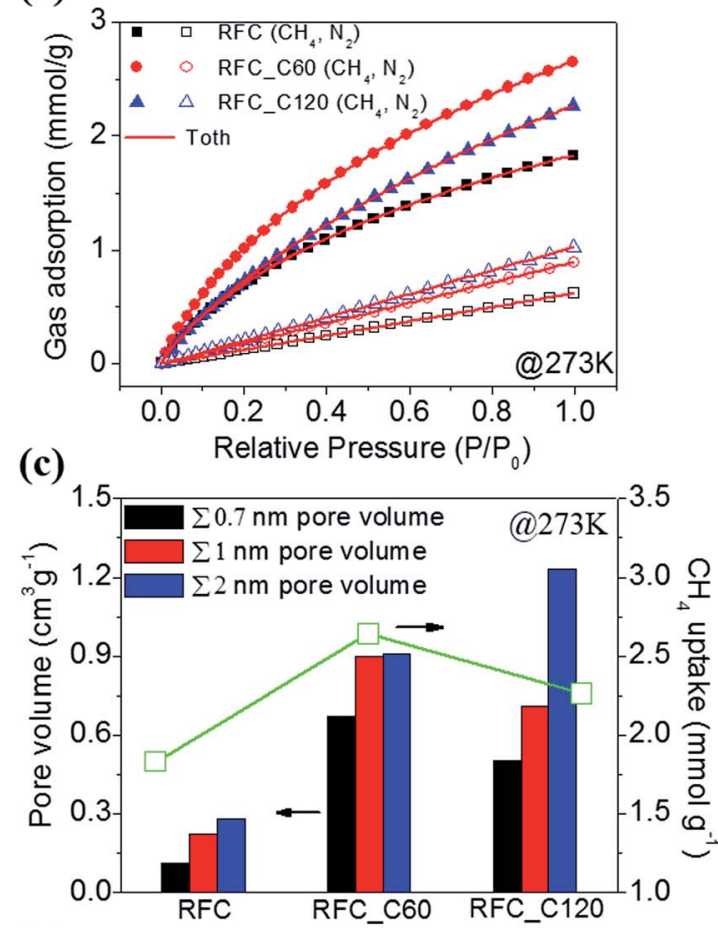

(e)

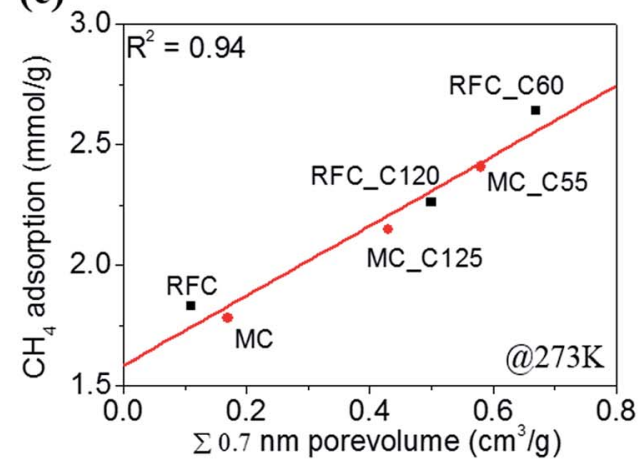

(b)

(d)
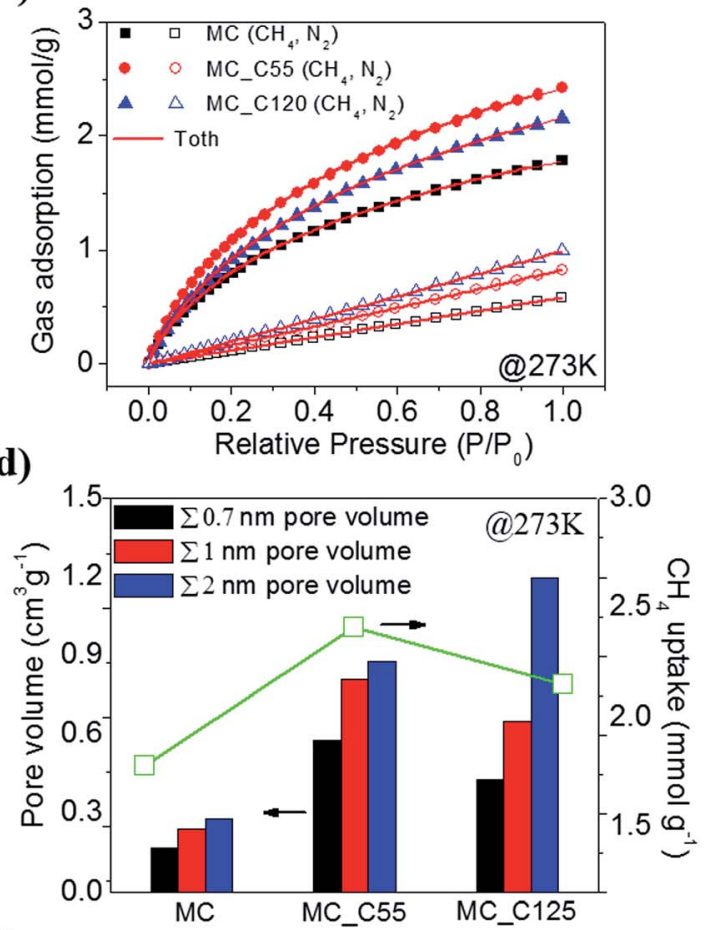

(f)

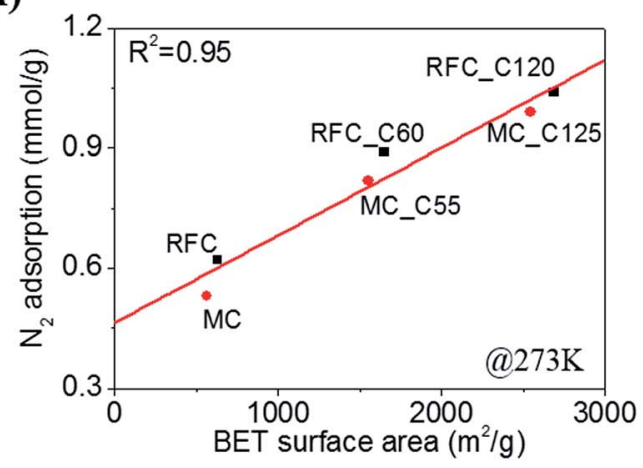

Fig. $6 \mathrm{CH}_{4}$ and $\mathrm{N}_{2}$ isotherm of RFC (a) and $\mathrm{MC}$ (b) samples at $273 \mathrm{~K}$ (red line is Töth isotherm fitting). Distribution of pore volumes between pores of less than $0.7 \mathrm{~nm}$ (black), less than $1 \mathrm{~nm}$ (red), and less than $2 \mathrm{~nm}$ (blue) of RFC (c) and MC (d) samples at $273 \mathrm{~K}$. Relationship plot of CH adsorption capacities with respect to accumulated ultramicropore volume of $0.7 \mathrm{~nm}(\mathrm{e})$ and relationship plot of $\mathrm{N}_{2}$ adsorption capacities with respect to BET surface area (f) of RFC and MC samples at $273 \mathrm{~K}$.

inferring that the surface heterogeneity of carbon surfaces strongly favors $\mathrm{CH}_{4}$ adsorption., ${ }^{4,46,47}$ Since the carbon samples with highest $\mathrm{CH}_{4}$ uptake present lowest $n$ values $(0.5-0.52$ for RFC_C60 and 0.51-0.54 for MC_C55), it turns out that the role ultramicroporosity is pivotal to enhance the $\mathrm{CH}_{4}$ uptake capacity. On the other hands, the values of heterogeneity parameters of $\mathrm{N}_{2}$ on the carbon samples (Table $\mathrm{S} 2 \dagger$ ) are closed to unity, suggesting the less interaction between $\mathrm{N}_{2}$ and the carbon surface.

The isosteric heat of adsorption $\left(Q_{\mathrm{st}}\right)$ values of carbon samples also suggest the same trend (Table 1). Therefore, the development of ultramicropores is pivotal to enhance $\mathrm{CH}_{4}$ adsorption capacity at equilibrium adsorption under ambient conditions. To further elucidate the importance of ultramicropores for $\mathrm{CH}_{4}$ adsorption, $\mathrm{CH}_{4}$ adsorption capacities of both carbon samples are plotted with respect to accumulated ultramicropore volume ( $<0.7 \mathrm{~nm}$ and $<1 \mathrm{~nm})$ (Fig. 6e and S4a†).

Good correlation $\left(R^{2}=0.94\right)$ is obtained for accumulated ultramicropore volumes. In contrast, no correlation is obtained for accumulated pore volume up to $2 \mathrm{~nm}$ and SSA (Fig. S4b and $\mathrm{c} \dagger$ ), strongly indicating the importance of ultramicropore development. Such high correlation also indicates that polarity derived from $\mathrm{N}$-doping on the carbon surface is not related to $\mathrm{CH}_{4}$ adsorption due to the nonpolar nature of $\mathrm{CH}_{4} \cdot{ }^{1,2,17}$

The adsorption-based selectivities of $\mathrm{CH}_{4}$ over $\mathrm{N}_{2}$ for RFC and MC samples at $273 \mathrm{~K}$ and $298 \mathrm{~K}$ are calculated using the ratio of Henry's law constants derived from single gas isotherms (Tables 1 and $\mathrm{S} 3 \dagger$ ).

The selectivity trend at $298 \mathrm{~K}$ for RFC samples (RFC, RFC_C60, and C120) and MC samples (MC, MC_C55, and C125) 
Table 2 Comparison of $\mathrm{CH}_{4}$ adsorption and $\mathrm{CH}_{4} / \mathrm{N}_{2}$ selectivity of various absorbents measured at $273 \mathrm{~K}$ and $298 \mathrm{~K}$

\begin{tabular}{|c|c|c|c|}
\hline Sample & $\begin{array}{l}\mathrm{CH}_{4} \text { adsorption } 273 \mathrm{~K} / 298 \mathrm{~K} \\
\left(1 \mathrm{bar}, \mathrm{mmol} \mathrm{g}^{-1}\right)\end{array}$ & $\begin{array}{l}\text { Selectivity } 273 \mathrm{~K} / 298 \mathrm{~K} \\
\left(\mathrm{CH}_{4} / \mathrm{N}_{2}\right)\end{array}$ & Reference \\
\hline$\left[\mathrm{Ni}_{3}(\mathrm{HCOO})_{6}\right] / \mathrm{MOF}$ & $-/ 0.791$ & $-/ 6.02$ & Ref. 1 \\
\hline $\mathrm{Ni}$ formate/MOF & $-/ 0.75$ & $-/ 6.1$ & Ref. 2 \\
\hline AC G2X7/carbon & $1.9 / 1.3$ & $6.17 / 4.38$ & Ref. 3 \\
\hline MAC/carbon & $-/ 0.98$ & $-/ 3$ & Ref. 4 \\
\hline BPL calgon/carbon & $-/ 0.8$ & $-/ 5.0$ & Ref. 18 \\
\hline Poly(vinylidene chloride)-based carbon/carbon & $-/ 1.8$ & - & Ref. 19 \\
\hline $\mathrm{Hb} /$ zeolite & $0.8 / 0.6(303 \mathrm{~K})$ & $-/ 2(303 \mathrm{~K})$ & Ref. 20 \\
\hline Nab/zeolite & $0.6 / 0.4(303 \mathrm{~K})$ & $-/ 1.75(303 \mathrm{~K})$ & Ref. 20 \\
\hline DBT/porous polymer & $1.1 / 0.9$ & $8.0 / 7.6$ & Ref. 21 \\
\hline Basolite A 100/MOF & $1.12 / 0.71$ & $4.8 / 3.7$ & Ref. 22 \\
\hline MC_C55 & $2.41 / 1.62$ & $6.1 / 7.4$ & In this work \\
\hline
\end{tabular}

is very similar to the $\mathrm{CH}_{4}$ uptake capacities, which are $4.2,6.8$, and 5.3, and 5.3, 7.4, and 6.0, respectively. A similar trend is also observed for selectivities measured at $273 \mathrm{~K}$ (Table 1). Higher CH4 adsorption capacity due to the development of more ultramicropores results in higher $\mathrm{CH}_{4}$ over $\mathrm{N}_{2}$ selectivity, suggesting that differences in $\mathrm{CH}_{4}$ adsorption capacities between carbons is more sensitive than differences in $\mathrm{N}_{2}$ adsorption.

This result is further identified as a difference in Henry's constants (Table S $3 \dagger$ ). The development of ultramicropores is not only helpful for enhanced $\mathrm{CH}_{4}$ adsorption but also for high selectivity of separating $\mathrm{CH}_{4}$ over $\mathrm{N}_{2}$. With its higher polarizability value, $\mathrm{CH}_{4}$ is more sensitively adsorbed within ultramicropores rather than the less polarizable $\mathrm{N}_{2} \cdot{ }^{\mathbf{1 , 2 , 1 7}}$ Ideal adsorption selectivities of 6.8 for RFC_C60 and 7.4 for MC_C55 at $298 \mathrm{~K}$ are ones of the highest values comparable with those of MOFs, MOPs, and carbonaceous materials (Table 2). With combining the superb $\mathrm{CH}_{4}$ uptake capacities, such ultrahigh selectivities of $\mathrm{CO}_{2}$-activated RFC and $\mathrm{MC}$ carbons are highly desirable for adsorption-based UCN upgrading.

\subsection{Adsorption of heavy metal ions: role of SSA and polarity}

In attempts to elucidate the role of SSA and polarity of carbons, adsorption of heavy metal ions $\left(\mathrm{Fe}^{2+}, \mathrm{Sb}^{3+}\right.$, and $\left.\mathrm{Sb}^{5+}\right)$ is carried out using aqueous solutions at pH 5 under ambient condition. First, $\mathrm{Fe}^{2+}$ adsorption equilibrium isotherms for RFC samples (RFC, RFC_C60, C120, C250, and C380) and MC samples (MC, MC_C55, and C120) are measured as functions of time (Fig. 7a and b). The carbon samples of RFC, RFC_C60 and C120, MC, and MC_C55 reach adsorption equilibrium in less than $2 \mathrm{~h}$. Conversely, RFC_C250, C380, and MC_C125 require more than $6 \mathrm{~h}$ for adsorption saturation, strongly indicating the relationship of adsorption capacity and porosity. Then, equilibrium isotherms are fitted with the Langmuir isotherm model $^{\mathbf{2 6 - 3 0}}$ (detailed parameters are explained in the Experimental section).

Obtained $q_{\mathrm{m}}$ values from RFC samples are plotted with respect to SSA (Fig. 7c). A good relationship $\left(R^{2}=0.97\right)$ between the $q_{\mathrm{m}}$ values and SSAs of RFC samples is identified, as has been reported in the literature. ${ }^{49-53}$ Thus, the superb $q_{\mathrm{m}}$ value $\left(101 \mathrm{mg} \mathrm{g}^{-1}\right)$ for RFC_C390 is attributed to ultrahigh SSA of $3958 \mathrm{~m}^{2} \mathrm{~g}^{-1}$ derived from a prolonged $\mathrm{CO}_{2}$ activation process. When the $q_{\mathrm{m}}$ (a)

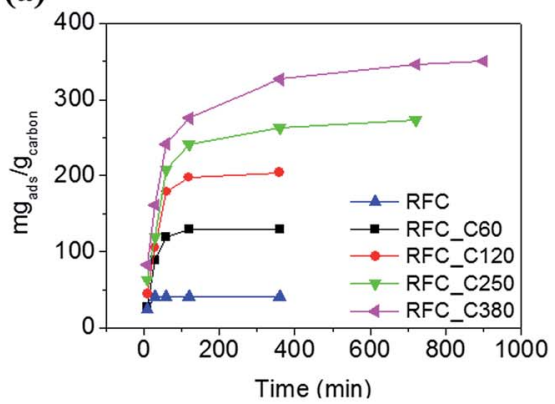

(b)

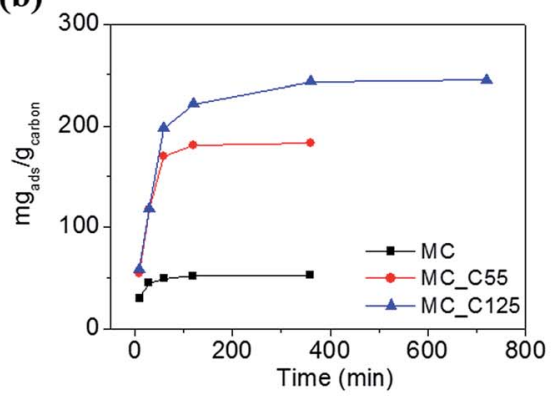

(c)

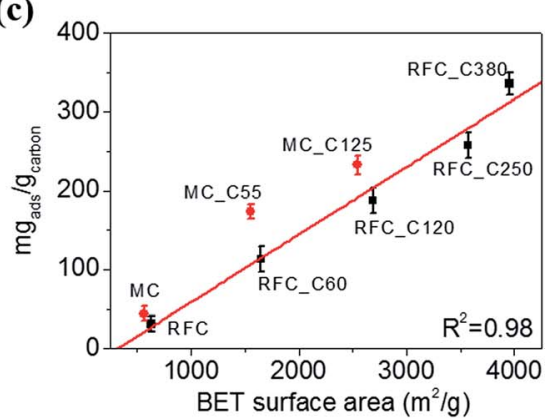

Fig. 7 Equilibrium isotherms of Fe ion adsorption of RFC (a) and MC (b) samples. Relationship plot of Fe ion adsorption capacities with respect to BET surface area (c). 
(a)

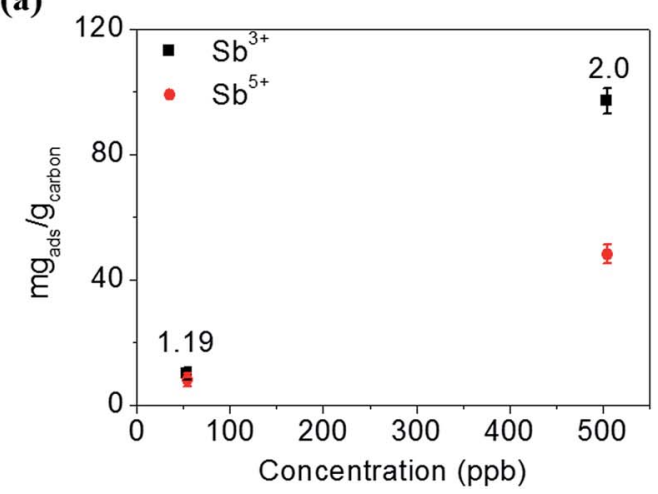

(b)

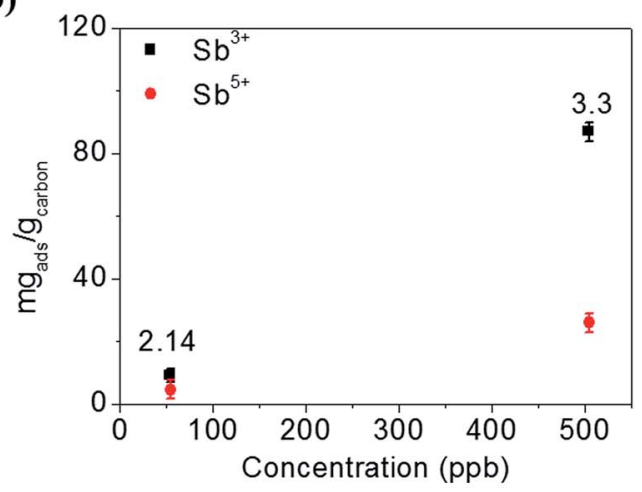

Fig. 8 Selectivity of $\mathrm{Sb}^{3+} / \mathrm{Sb}^{5+}$ using RFC_C60 (a) and MC_C55 (b) at 50 and $500 \mathrm{ppb}$ in $\mathrm{pH} 5$ buffer solution. (Inset number in figure is $\mathrm{Sb}^{3+} / \mathrm{Sb}^{5+}$ selectivity).

vales of MC samples are compared with those of RFC samples, they are located on the upper region of the plotted line, indicating a good correlation of the $q_{\mathrm{m}}$ values of RFC samples with SSA (Fig. 7c). According to nitrogen content and FT-IR analyses, surface polarity caused by $\mathrm{N}$-doping is attributed to higher adsorption capacity of $\mathrm{Fe}^{2+}$ under ambient conditions.

Another adsorption experiment that evaluates the polarity effect of carbons for selective adsorption of $\mathrm{Sb}^{3+}$ over $\mathrm{Sb}^{5+}$ is also performed. The selective adsorption experiment for $\mathrm{Sb}^{3+}$ over $\mathrm{Sb}^{5+}$ is achieved using RFC_C60 and MC_C55 samples with similar SSAs but different nitrogen contents (Table 1). Equimolar amounts of 50 and $500 \mathrm{ppb}$ of two Sb species are adsorbed on RFC_C60 and MC_C55 samples at pH 5. The adsorption capacities with associated selectivities for $\mathrm{Sb}^{3+}$ over $\mathrm{Sb}^{5+}$ of RFC_C60 and MC_C55 on different concentrations are plotted in Fig. 8a and b, respectively. The adsorption capacities for $\mathrm{Sb}^{3+}$ are very similar for both carbons, whereas the adsorption capacity trend for $\mathrm{Sb}^{5+}$ is quite different.

MC_C55 adsorbs substantially less $\mathrm{Sb}^{5+}$ than RFC_C60. Considering the charge characters of $\mathrm{Sb}$ species, $\mathrm{Sb}^{3+}$ (neutral charge as $\mathrm{Sb}(\mathrm{OH})_{3}$ ) and $\mathrm{Sb}^{5+}$ (negative charge as $\left.\mathrm{Sb}(\mathrm{OH})_{6}{ }^{-}\right)$, the different adsorption trends for $\mathrm{Sb}^{5+}$ are ascribed to the more basic MC_C55 preferentially adsorbing less negatively charged $\mathrm{Sb}^{5+}$ under the specific conditions. Therefore, the higher selectivity of MC_C55 compared to RFC_C60 of up to 3.3 for $\mathrm{Sb}^{3+}$ over $\mathrm{Sb}^{5+}$ is accomplished. This result indicates the role of polarity in selective adsorption of metal ions.

\section{Conclusions}

The role of porosity and polarity of carbonaceous materials for selective separation of $\mathrm{CH}_{4}$ over $\mathrm{N}_{2}$, adsorption of heavy metal ions, and selective adsorption of $\mathrm{Sb}$ species were elucidated using synthesized carbon spheres with different $\mathrm{N}$-doping levels. Hot $\mathrm{CO}_{2}$ treatment allows fine-control of the PSA and SSA of RFC and highly N-doped MC samples. The development of ultramicropores is highly desirable for enhanced $\mathrm{CH}_{4}$ uptake regardless of the surface polarity of carbons, which eventually results in ultrahigh selectivity for $\mathrm{CH}_{4}$ over $\mathrm{N}_{2}$. The $\mathrm{CH}_{4}$ adsorption capacities of the most developed ultramicopores of RFC_C60 and MC_C55 are 2.64 and $2.41 \mathrm{mmol} \mathrm{g}^{-1}$ at $273 \mathrm{~K}$ ( 1 bar), respectively, and there carbons also have superb selectivities of $\mathrm{CH}_{4}$ over $\mathrm{N}_{2}$ of 6.8 and 7.1 at $298 \mathrm{~K}$, respectively, which are ones of the best values for $\mathrm{CH}_{4}$ adsorbents. In addition, $\mathrm{Fe}^{2+}$ ion is more adsorbed on carbons with higher SSAs. N-doped MC samples present higher adsorption capacities over RFC samples. Higher selective adsorption for $\mathrm{Sb}^{3+}$ over $\mathrm{Sb}^{5+}$ is accomplished for the basic MC_C55 sample, strongly suggesting that the choice of carbon surface polarity is important for selective metal ion adsorption. Distinct correlations between porosity and polarity of carbons, adsorption capacities for $\mathrm{CH}_{4}$, ultrahigh selectivity for $\mathrm{CH}_{4}$ over $\mathrm{N}_{2}$, and metal ions are exclusively elucidated. The results provide design principles for nanoporous carbonaceous materials and use in specific adsorption applications.

\section{Conflicts of interest}

There are no conflicts to declare.

\section{Acknowledgements}

The authors thank Prof. H. Chun regarding $\mathrm{CH} 4$ adsorption. This work was supported by the Korea Environmental Industry and Technology Institute (KEITI, No. 2016000200005).

\section{References}

1 J. A. Delgado, M. A. Uguina, J. L. Sotelo and B. Ruiz, Sep. Purif. Technol., 2006, 50, 192-203.

2 B. Yuan, X. Wu, Y. Chen, J. Huang, H. Luo and S. Deng, Environ. Sci. Technol., 2013, 47, 5474-5480.

3 M. S. A. Baksh, R. T. Yang and D. D. L. Chung, Carbon, 1989, 27, 931-934.

4 J. Cai, J. Qi, C. Yang and X. Zhao, ACS Appl. Mater. Interfaces, 2014, 6, 3703-3711.

5 X. Xu, X. Zhao, L. Sun and X. Liu, J. Nat. Gas Chem., 2008, 17, 391-396. 
6 N. K. Jensen, T. E. Rufford, G. Watson, D. K. Zhang, K. I. Chan and E. F. May, J. Chem. Eng. Data, 2011, 57, 106113.

7 J. Hu, T. Sun, X. Liu, Y. Guo and S. Wang, RSC Adv., 2016, 6, 64039-64046.

8 X. Ren, T. Sun, J. Hu and S. Wang, Microporous Mesoporous Mater., 2014, 186, 137-145.

9 J. Möllmer, M. Lange, A. Möller, C. Patzschke, K. Stein, D. Lässig, J. Lincke, R. Gläser, H. Krautscheid and R. Staudt, J. Mater. Chem., 2012, 22, 10274-10286.

10 Y.-X. Hu, S.-C. Xiang, W.-W. Zhang, Z.-X. Zhang, L. Wang, J.-F. Bai and B. Chen, Chem. Commun., 2009, 7551-7553.

11 M. Saleh, H. M. Lee, K. C. Kemp and K. S. Kim, ACS Appl. Mater. Interfaces, 2014, 6, 7325-7333.

12 A. Olajossy, A. Gawdzik, Z. Budner and J. Dula, Chem. Eng. Res. Des., 2003, 81, 474-482.

13 H. Yi, F. Li, P. Ning, X. Tang, J. Peng, Y. Li and H. Deng, Chem. Eng. J., 2013, 215, 635-664.

14 R. T. Yang, Adsorbents: fundamentals and applications, John Wiley \& Sons, 2003.

15 R. T. Yang, Gas separation by adsorption processes, Butterworth-Heinemann, 2013.

16 D. M. Ruthven, Chem. Eng. Technol., 2011, 83, 44-52.

17 S. Ma and H.-C. Zhou, Chem. Commun., 2010, 46, 44-53.

18 D. Lässig, J. Lincke, J. Moellmer, C. Reichenbach, A. Moeller, R. Gläser, G. Kalies, K. A. Cychosz, M. Thommes and R. Staudt, Angew. Chem., Int. Ed., 2011, 50, 10344-10348.

19 Y. Li, T. Ben, B. Zhang, Y. Fu and S. Qiu, Sci. Rep., 2013, 3, 2420-2425.

20 L. Bastin, P. S. Bárcia, E. J. Hurtado, J. A. Silva, A. E. Rodrigues and B. Chen, J. Phys. Chem. C, 2008, 112, 1575-1581.

21 B. Liu and B. Smit, Langmuir, 2009, 25, 5918-5926.

22 Y. Zhu, H. Long and W. Zhang, Chem. Mater., 2013, 25, 16301635.

23 B. Liu and B. Smit, J. Phys. Chem. C, 2010, 114, 8515-8522.

24 E. Haldoupis, S. Nair and D. S. Sholl, J. Am. Chem. Soc., 2012, 134, 4313-4323.

25 B. Ashourirad, A. K. Sekizkardes, S. Altarawneh and H. M. ElKaderi, Chem. Mater., 2015, 27, 1349-1358.

26 X. Luo, X. Lei, N. Cai, X. Xie, Y. Xue and F. Yu, ACS Sustainable Chem. Eng., 2016, 4, 3960-3969.

27 B. Yang, C. Yu, Q. Yu, X. Zhang, Z. Li and L. Lei, RSC Adv., 2015, 5, 7182-7191.

28 X. Li, H. Zhou, W. Wu, S. Wei, Y. Xu and Y. Kuang, J. Colloid Interface Sci., 2015, 448, 389-397.

29 G.-X. Yang and H. Jiang, Water Res., 2014, 48, 396-405.

30 Z. Zhang, Z. Dong, Y. Dai, S. Xiao, X. Cao, Y. Liu, W. Guo, M. Luo and Z. Le, RSC Adv., 2016, 6, 102462-102471.
31 K. Simeonidis, V. Papadopoulou, S. Tresintsi, E. Kokkinos, I. A. Katsoyiannis, A. I. Zouboulis and M. Mitrakas, Sustainability, 2017, 9, 238.

32 X. Guo, Z. Wu, M. He, X. Meng, X. Jin, N. Qiu and J. Zhang, J. Hazard. Mater., 2014, 276, 339-345.

33 A. Sarı, G. N. R. Şahinoğlu and M. Tüzen, Ind. Eng. Chem. Res., 2012, 51, 6877-6886.

34 U. EPA, US Environmental Protection Agency, Washington, DC, EPA, 2006.

35 S. Risica and S. Grande, RAPPORTI ISTISAN, 2000.

36 M. Krachler, H. Emons and J. Zheng, Trends Anal. Chem., 2001, 20, 79-90.

37 L. Nemes and L. Bulgariu, Open Chem., 2016, 14, 175-187.

38 J. Liu, S. Z. Qiao, H. Liu, J. Chen, A. Orpe, D. Zhao and G. Q. M. Lu, Angew. Chem., Int. Ed., 2011, 50, 5947-5951.

39 H. S. Kim, M. S. Kang and W. C. Yoo, J. Phys. Chem. C, 2015, 119, 28512.

40 K.-Y. Ju, Y. Lee, S. Lee, S. B. Park and J.-K. Lee, Biomacromolecules, 2011, 12, 625-632.

41 N. P. Wickramaratne and M. Jaroniec, ACS Appl. Mater. Interfaces, 2013, 5, 1849-1855.

42 M. Kim, H. S. Kim, S. J. Yoo, W. C. Yoo and Y.-E. Sung, J. Mater. Chem. A, 2017, 5, 4199-4206.

43 N. P. Wickramaratne, J. Xu, M. Wang, L. Zhu, L. Dai and M. Jaroniec, Chem. Mater., 2014, 26, 2820-2828.

44 D. D. Do, Adsorption Analysis: Equilibria and Kinetics: (With CD Containing Computer Matlab Programs), World Scientific, 1998.

45 S. Loh, K. A. Rahman, A. Chakraborty, B. B. Saha, Y. S. Choo, B. C. Khoo and K. C. Ng, J. Chem. Eng. Data, 2010, 55, 28402847.

46 D. P. Vargas, L. Giraldo and J. C. Moreno-Pirajan, Int. J. Mol. Sci., 2012, 13, 8388-8397.

47 A. P. Terzyk, J. Chatlas, P. A. Gauden, G. Rychlicki and P. Kowalczyk, J. Colloid Interface Sci., 2003, 266, 473-476.

48 D. Park, Y. Moon, H. Kim, H. Ahn and C. Lee, Adsorption, 2014, 20, 631-647.

49 Y. Ying, A. M. Ribeiro, L. Ping, J. G. Yu and A. E. Rodrigues, Ind. Eng. Chem. Res., 2014, 53, 16840-16850.

50 K. Kadirvelu and C. Namasivayam, Adv. Environ. Res., 2003, 7, 471-478.

51 M. Prasad, S. Saxena and S. Amritphale, Ind. Eng. Chem. Res., 2002, 41, 105-111.

52 I. E. M. Carpio, J. D. Mangadlao, H. N. Nguyen, R. C. Advincula and D. F. Rodrigues, Carbon, 2014, 77, 289-301.

53 M. Myglovets, O. Poddubnaya, O. Sevastyanova, M. E. Lindström, B. Gawdzik, M. Sobiesiak, M. Tsyba, V. Sapsay, D. Klymchuk and A. Puziy, Carbon, 2014, 80, 771-783. 